\title{
Introducing WebQuests in Mathematics: A Study of Qatari Students' Reactions and Emotions
}

\author{
Carol Murphy ${ }^{1 *}$, Nigel Calder ${ }^{2}$, Nasser Mansour ${ }^{3}$, Abdullah Abu-Tineh ${ }^{4}$ \\ ${ }^{1}$ University of Tasmania, AUSTRALIA \\ 2 University of Waikato, NEW ZEALAND \\ ${ }^{3}$ University of Exeter, UNITED KINGDOM \\ ${ }^{4}$ Qatar University, QATAR \\ *CORRESPONDENCE: $\otimes$ carol.murphy@utas.edu.au
}

\begin{abstract}
There is a need to investigate didactic strategies that can enhance engagement in science and mathematics education. This paper reports on the introduction of WebQuests, as part of collaborative inquiry, to enhance students' engagement in their mathematics lessons in Qatar. We present interview data gathered from eight student focus groups (grades 5 to 9) before and after the introduction of WebQuest lessons. Constant comparative analysis was used to examine students' reactions to using WebQuests in developing student-directed learning and collaboration in relation to support for learning. The analysis identified prospective reactions that were often confirmed retrospectively following the WebQuest lessons. These reactions were further analysed as external expressions of affect encoded by trait-like emotions that were similar to Goldin et al.'s (2011) notion of engagement structures. We suggest that the confirmation of reactions and emotions was influenced by students' levels of tolerance for ambiguity as a common element across engagement structures.
\end{abstract}

Keywords: collaborative inquiry, emotions, engagement structures, exploratory talk, WebQuests

\section{INTRODUCTION}

There is an international consensus that a knowledge-based innovative economy relies on a strong science education system in schools (Gluckman, 2011). In this regard, the Qatar Ministry of Education sees the promotion of science, technology, engineering, and mathematics (STEM) as key to education (Qatar National Research Strategy (QNRS), 2012). Despite these promotions, many students in Qatar are disengaged and disinterested in science and mathematics, and the subjects are often unpopular to study at secondary and tertiary levels (Said \& Friesen, 2013).

In Qatar, traditional transmissive teacher-directed pedagogies have dominated (BouJaoude, 2003), but there has been a move to introduce inquiry-based approaches and collaborative student-centred learning. Mathematics teaching in Qatar follows the national curriculum standards established by the Curriculum Standards Office (CSO). Skills such as critical thinking, inquiry, and reasoning are emphasised, and the use of digital technology is promoted in mathematics. Whilst a few schools in Qatar have introduced inquiry-based learning, this practice still does not dominate. The persistence of more traditional practices may be due to ineffective models of professional development (PD) in Qatar (Palmer et al., 2016), and point towards the need for $\mathrm{PD}$ to include practical manageable classroom strategies.

Article History: Received 5 December $2019 \bullet$ Revised 9 July $2020 \bullet$ Accepted 13 July 2020

(C) 2020 by the authors; licensee Modestum. Open Access terms of the Creative Commons Attribution 4.0 International License (http://creativecommons.org/licenses/by/4.0/) apply. The license permits unrestricted use, distribution, and reproduction in any medium, on the condition that users give exact credit to the original author(s) and the source, provide a link to the Creative Commons license, and indicate if they made any changes. 
In this article, we present data from part of a larger intervention project that involved the evaluation of the effectiveness of a Professional Development (PD) programme based on the use of two didactic tools; WebQuests and exploratory talk. Both didactic tools provide practical, manageable, explicit strategies for teachers and students to use in their classrooms and were intended to support a shift in pedagogy towards collaborative inquiry. Several research studies suggest that WebQuests can inspire students to investigate and research answers to questions (e.g., Calder, 2011; Salsovic, 2007), but their use in Qatari schools was relatively unknown. Similarly, exploratory talk strategies have been shown to support dialogue and collaborative group work (e.g., Littleton \& Mercer, 2013), and, again, such strategies were unknown in Qatar. The intervention project was aimed at students grades 5 to 9 as previous research has shown that it is in these middle years that student attitudes decline in science and mathematics (e.g., Frenzel, Goetz, Pekrun, \& Watt, 2014; Kind, Jones, \& Barmby, 2007; Potvin \& Hansi, 2014).

Research has suggested that inquiry-based pedagogies can enhance student engagement in learning STEM subjects (Fullan \& Langworthy, 2014; Hattie, 2009; Lederman, Lederman, \& Antink, 2013; Maas \& Artigue, 2013). Activities that present perceived control for students can help them to value the activity and respond positively (Pekrun, 2006) with the consequence that their engagement is enhanced. Hence, our premise was that the use of these strategies would help scaffold students towards inquiry-based approaches to learning and, consequently, enhance engagement. However, we were aware there may be tensions, as the introduction of inquiry approaches would mean a move away from teacher-directed traditions towards a pedagogy that might be new for many of the teachers and students. Previous studies have explored the tensions for teachers in introducing inquiry-based pedagogies, (e.g., Dole, Bloom, \& Kowalske, 2016; Grant \& Hill, 2006), fewer studies have explored the potential tensions for students in the introduction of such pedagogies (Lederman et al., 2013).

In this article we focus on the initial introduction of the two didactic tools; WebQuests and exploratory talk. Based on our assumption that the tools would provide practical manageable strategies within the PD programme, we anticipated a change in teaching approaches towards collaborative inquiry. Our interest was to investigate students' reactions to their initial use in mathematics classroom in the second year of the project. We present students' prospective reactions towards the introduction of the tools and their retrospective reactions after two school terms in their mathematics classrooms. Our intention was to determine any changes in students' reactions that might indicate whether the tools had helped them move towards an inquiry approach in a way that engaged them in their learning in mathematics.

We first present our interpretation of collaborative inquiry and combined use of the didactic tools in relation to the aims and research questions. Theoretical notions of reactions, emotions, and engagement are explored and used to underpin the research methodology and analytical framework. Results from focus groups interviews are presented and discussed in relation theoretical concepts. Conclusions consider the confirmation of student reactions and their consequent impediment on the introduction of collaborative inquiry.

\section{DEVELOPING COLLABORATIVE INQUIRY}

The study focuses on the notion of inquiry as collaborative and student-directed, involving collective sensemaking that relates to a way of working in classrooms where knowledge is constructed and re-constructed between participants in specific contexts (Wells, 2001). This notion is consistent with a view of knowledge as a generative process of meaning-making, rather than the acquisition of a stable body of facts content (Mansour \& Wegerif, 2013), and with a view of learning as active participation about questions or topics that are of interest to the students.

In addition, we refer to a continuum model of pedagogy in relation to inquiry (Knowles, 1975; Tafoya, Sunal, \& Knecht, 1980). At one end is teacher direction where there is little or no inquiry. The teacher tells students the outcome of a problem and gives instructions on how to carry out a problem. Pedagogy relates to one-way linear monologues as students receive knowledge from one authority, the teacher or text book. In the middle of the continuum is guided inquiry, where the teacher gives prompts or questions as a starting point, and students find their own way to answer the question. At the other end is a full open inquiry where students initiate their own questions and formulate their own processes to answer their questions. A shift along this continuum means a shift in pedagogy from a linear monologue, where knowledge is directed by the teacher, towards a dialectic interplay of knowledge (Artigue \& Blomhøj, 2013) amongst the students as they discover knowledge by examining and investigating competitive ideas. At this dialectic end of the continuum, the teacher's role is not to present information and procedures to the class that the students then memorise and 
practice. Instead, the teacher is an arbiter of legitimate cultural knowledge as students collaborate to question and discuss answers and findings.

Whilst a shift towards collaborative inquiry as a student-directed approach to learning has been seen to improve attitudes and enhance engagement in STEM subjects, the subsequent changes in classroom norms may be unsettling for some students. In a teacher-directed approach, a teacher has a firm grasp on the subject content and leads the students towards solutions. The dialectic nature of collaborative inquiry means the teacher no longer directs the process and steps for students. Instead, the teacher orchestrates and facilitates the learning processes (Calleja, 2016). In this way, the responsibility for learning shifts from teacher to student (Grant \& Hill, 2006). Students may perceive that their teacher is no longer in command of the content being taught, and they are being asked to follow multiple pathways to find the knowledge themselves with the potential for making mistakes (Lipman, 2003). The classroom environment may feel less controlled, disquieting and uncomfortable as students are encouraged to ask questions and examine possibilities (Foster, 2014).

In encouraging collaboration within inquiry, we were also introducing a social-behavioural change. Some studies have indicated that collaboration can have a positive impact on students' attitudes towards mathematics. For example, Linnenbrink-Garcia, Rogat, and Koskey's (2011) study suggested that small group collaboration created a reciprocal dynamic relationship between affect and engagement where the quality of group interactions helped to shape affect. Again, these studies do not account for the potential disquieting experiences, such as arriving at wrong answers or following blind alleys (Goldin, Epstien, Schorr, \& Warner, 2011). Whilst some students may find collaboration engaging, others may find that the disagreements and criticisms are uncomfortable or stressful.

The collaborative model of inquiry adopted for this study suggests that the dialectic nature of inquiry is promoted as a key part of student-directed approaches. However, the dialectic nature requires students to accept new roles and responsibilities in learning and to tolerate ambiguity, that is to perceive uncertainties, contradictions, and multiple meanings in an open way (Bochner, 1965; Frenkel-Brunswik, 1949; Mclain, Kefallonitis, \& Armani, 2015). Studies have focused on teacher-related issues concerning tolerance for ambiguity (e.g., Dole, Bloom, \& Kowalske, 2016; Grant \& Hill, 2006), and on students' experiences of ambiguity in their learning at tertiary level (e.g., Edens, 2000), but little is yet known about students' experiences in school settings. Our intention was to investigate such issues with middle school students in Qatar and explore their reactions to the introduction of collaborative student-directed inquiry approaches in mathematics.

\section{DIDACTIC STRATEGIES}

Our premise for the study was that the introduction of two didactic tools, WebQuests and exploratory talk, would support both teachers and students in a move along the continuum from teacher-directed towards student-directed elements of guided collaborative inquiry and to investigate if the tools help to address stresses and discomforts. Whilst not a focus of this paper, we provide a short outline of these two strategies to situate the context of the study.

WebQuests relate to "an inquiry-orientated activity in which some or all of the information that learners interact with come(s) from resources on the internet" (Dodge, 1995, p. 1). The students are given a task to focus on in relation to their learning. Depending on their experience, the students are given a structured or open process to research the task with a focused set of possible websites. The structure of the process enables students to research answers to their questions. Students are required to examine information accessed on the internet and to determine information and mis-information. Hence, they apply criticality in making their thinking clear in the way they use information to inform their own ideas about mathematics within an investigation (Calder, 2011; Salsovic, 2007). Previous research has shown that the use of WebQuests in different curriculum areas have impacted positively on student engagement (e.g. Lappas \& Kritikos, 2018; Lipscomb, 2003; Noording, Samed, \& Razali, 2008), and Üzel's (2012) study indicated that WebQuests had a positive influence on primary school students' motivation in mathematics. Whilst the nature of WebQuests is designed to encourage critical thinking and inquiry, several researchers, such as Lipscomb (2003), provided suggestions for implementing them successfully, and these suggestions guided their use in this study.

The notion of exploratory talk was developed both as a phenomenon in classroom communication (Barnes, 1975) and as a series of didactic strategies to encourage joint, explicit, collaborative reasoning among students (Littleton \& Mercer, 2013). The strategies include the development of key prompts to support students in investigating tentative answers, justifying their decisions and working towards a group agreement. 
Implementation of these strategies has helped teachers understand the role of talk in supporting learning (Mercer, Wegerif, \& Dawes, 1999), and has promoted constructive student engagement with digital technologies (Mercer \& Sams, 2006).

From existing research evidence, our premise was that the introduction of these two didactic tools as part of a PD intervention would provide authentic contexts related to inquiry, support student collaboration in small group work, and, consequently, scaffold a shift towards student-directed collaborative inquiry. Whilst the strategies have emerged as two distinct tools, we used them in conjunction with each other. The WebQuests provide the authentic context and the exploratory talk strategies would support students in asking each other questions, presenting tentative answers, and in making and justifying decisions in these contexts. As such, it was anticipated that the conjoined strategies within these two tools would support a move towards a dialectic interplay. In addition, the two didactic tools could be used within the current Qatari national curriculum and timetabling constraints. In that way, they were seen to present manageable practical classroom strategies. From now on, we refer to the use of the combined strategies within the tools as the WebQuest lessons.

\section{AIMS AND RESEARCH QUESTIONS}

Despite our assumptions about the use of the strategies in the WebQuest lessons, we were aware that the traditional teacher-directed approaches of Qatari classrooms would be challenged, and that we were asking for transformations of classroom practices and learning environments. For some students, these changes might be challenging and engaging but for others they may be disquieting, particularly in relation to ambiguity. Our interest was whether the conjunction of the strategies in the WebQuest lessons had the potential to help students tolerate ambiguity associated with the dialectic interplay of collaborative inquiry. We intended to investigate the reactions of the students, before and after the introduction of the WebQuest lessons, and relate these reactions to emotions and engagement in learning mathematics during the initial stages of introducing a new pedagogy.

Qualitative interview data from eight student focus groups (FGs) (grades 5 to 9) were gathered pre- and post-introduction to identify students' prospective reactions towards the introduction of WebQuest lessons and their retrospective reactions following the two terms of WebQuest lessons. Our intention was to determine whether students' reactions, were changed or confirmed, following the introduction of the WebQuest lessons, and related to research question 1.

1. In what ways did the introduction of WebQuest lessons confirm or change students' reactions to a student-directed collaborative approach to learning?

We also anticipated that these reactions would present external expressions of affect encoded by trait-like emotions (Goldin, Epstein, Schorr, \& Warner, 2011) and our intention was to determine what emotions were evident within these reactions. Hence research question 2 :

2. What emotions were expressed in the reactions and how were they transformed, confirmed or emerged?

We viewed emotions as a key construct that related to engagement in mathematical learning experiences and could be conceptualised in a trait-like way (Goldin, 2014). Hence, a third research question was:

3. How might the confirmation, transformation or emergence of emotions indicate traits related to inquiry approaches to learning in mathematics?

\section{REACTIONS, TRAIT-LIKE EMOTIONS, AND ENGAGEMENT STRUCTURES}

One difficulty in researching affective constructs is the wide field of research traditions and, consequently, different interpretations and definitions. For example, one simple interpretation of attitude is an individual's negative or positive reaction towards an object, subject or idea resulting in a judgement as to whether the object is good, bad, harmful, pleasant, unpleasant, important, unimportant and so on (Crano \& Prislin, 2006). Such an interpretation posits attitudes as learned, relatively stable predispositions or tendencies (Ajzen, 2001). However, more recent research (e.g. Liljedahl, Oesterle, \& Bernèche, 2010) has suggested that attitudes can be modified, and that learning environments and teaching methods can influence these modifications.

Furthermore, whilst previous interpretations distinguish attitude from beliefs and emotions (McLeod, 1994), more recent interpretations blur these distinctions and relate attitude to emotional dispositions in a way that is relatively indistinguishable from beliefs (Di Martino \& Zan, 2001). This interpretation is further emphasised by Hannula (2002) in relating the cognitive element of emotions within attitude, and that 
emotions are connected to personal achievement orientation goals that influence how we react and function as we adapt to new situations.

These more recent interpretations of attitude suggest a type of evaluation, or reaction, to an experience or situation of learning. Students react to the experience or situation by relating to the novelty of the experience and their previous experiences in relation to their personal and cognitive goals. Hence, they posit a less stable construct relating to emotions and cognition, and different emotional-cognitive processes "produce an expression of an evaluation of mathematics" (Hannula, ibid., p.29). Such an interpretation suggests that attitudes refer to emotion and cognition but also relate to what we value and deem important; how we evaluate objects and events and so predict behaviour.

This view of attitude in relation to emotions, cognition and values is reflected in recent conceptualisations of engagement. Previously determined as a psychological investment in and effort directed toward learning, understanding or mastering knowledge (Merton (1968), more recent research suggests a multi-dimensional conceptualisation of engagement (e.g. Goldin, Epstein, Schorr, \& Warner, 2011; Turner \& Meyer, 2009). Attard (2014) and Lazarides and Rubach (2017) posited that engagement also involves behavioural dimensions, hence, drawing on conative notions of willingness to participate and exert effort as well as emotional reactions.

Goldin (2014) furthered an interpretation of emotions as part of an affective architecture that links cognition, attitudes, beliefs/values, social interactions, cultural norms, and roles. Emotion, in relation to engagement, is situation and event dependent (Goldin, 2014); how someone typically feels when situated in mathematics and in the context of learning in mathematics (e.g. problem solving). In this interpretation, emotions characterise an individual student's typical response in mathematical situations, suggesting that there may be patterns of regularities related to behavioural and motivational orientations. Emotions become active in certain social-mathematical situations and indicate interactions with cognition, social environment, emotions of others and the individual's traits. Where emotions become active, they may be indicative of more trait-like dispositions or engagement structures (Goldin, et al., 2011) and indicate "recurring, dynamical patterns of interaction" (p. 548).

From this interpretation Goldin et al. developed the notion of engagement structures as in-the-moment studies of desires, emotions, and behaviours when students engage in problem solving. These structures were seen to be "situated in the individual but become active in certain social/mathematical situations (Goldin, 2014, p. 405). Examples of engagement structures include Get The Job Done as a trait-like characteristic towards procedural approaches to getting answers, Look How Smart I Am as a trait-like disposition towards self-efficacy and mathematical ability, and Stay Out Of Trouble as a trait towards avoiding conflict. Such engagement structures are activated in learning situations.

As we intended to identify emotions encoded in the students' prospective and retrospective reactions, we were studying transition reactions and not in-the-moment emotions and behaviours. We saw advantage in examining transition reactions as they were more likely to reflect trait-like behavioural and motivational orientations. We further anticipated that, these trait-like emotions could be similar to Goldin et al.'s (2011) engagement structures.

\section{CONTEXT OF THE STUDY}

Teaching approaches in Qatar have been mainly associated with traditional teacher-directed pedagogies. Schools are separated by gender, and the education system is organised into pre-school (years 3 to 5), primary (grades 1 to 6 ), and secondary (preparatory grades 7 to 9 , and general or technical secondary grades 10 to 12 ). In the larger project, we worked with students from primary schools (grades 5 and 6) and from secondary preparatory schools (grades 7 to 9). Instruction in these schools was in Arabic. Mathematics and science were taught by specialist teachers both in primary and preparatory grades.

The lifetime of the larger project was over three years. The first year involved eight teachers (four science teachers and four mathematics teachers) in a pilot introduction of the PD. The second year involved sixteen teachers (eight science teachers and eight mathematics teachers) from eight schools. Eight PDSs (four specialists in mathematics and four specialists in science) worked with the teachers. The PDSs presented initial workshops and provided in-class support at intervals across the two school terms, when the WebQuest lessons were introduced. The third year of the project involved the voluntary establishment of schools as learning centres for continued dissemination of practice. 
Table 1. Participant mathematics classes in the second year of the project

\begin{tabular}{lll}
\hline School & Class & WebQuest lesson Topics \\
\hline I (Prep) & Grade 8; Boys & $\begin{array}{l}\text { Volume of cube and cuboid } \\
\text { Probability }\end{array}$ \\
\hline J (Primary) & Grade 5; Girls & $\begin{array}{l}\text { Angles of triangles } \\
\text { Units of mass }\end{array}$ \\
\hline L (Prep) & Grade 7; Girls & $\begin{array}{l}\text { Average speed } \\
\text { Area of composite shapes }\end{array}$ \\
& Grade 5; Girls & $\begin{array}{l}\text { Angle relationships } \\
\text { Sum of angles in a triangle }\end{array}$ \\
\hline $\mathrm{M}$ (Primary) & Grade 5; Girls & $\begin{array}{l}\text { Perimeter of rectangles } \\
\text { Perimeter of squares }\end{array}$ \\
\hline $\mathrm{N}$ (Primary) & Grade 6; Girls & $\begin{array}{l}\text { Division with decimals } \\
\text { Percentages }\end{array}$ \\
& & $\begin{array}{l}\text { Ratio and proportion } \\
\text { Area of composite shapes }\end{array}$ \\
& & Area of circle \\
P (Prep) & Grobability of simple events \\
\hline P (Prep) & Grade 9; Girls & Dilation \\
& & Solving linear equations \\
\hline
\end{tabular}

The data focused on in the study presented in this article were from the second year of the project when the major intervention took place. In this second year, participant students came from six girls' schools and two boys' schools. Students were predominantly Arabic, either Qatari or other Arabic nationalities, with a minority of students from Pakistani backgrounds (generally 10\% to 20\%). Table 1 presents the schools, and grades of each class involved in the second year.

Each class had 20-25 students. Students received six to seven mathematics classes a week. The eight teachers had a range of teaching experiences from two years to twenty-two years. All the teachers had at least degree-level qualification, either in mathematics or in education with a specialisation in mathematics. Teachers were asked to implement at least two WebQuest lessons over the course of the two terms. The topics of the WebQuests are presented in Table 1.

\section{RESEARCH METHODS}

The data analysed in this article were gathered from eight student FG interviews, one FG from each class I to $\mathrm{P}$. The interviews were carried out before and at the end of the two terms when the teachers introduced the WebQuest lessons. Each student FG had 6-10 students and interviews were carried out by researchers in Qatar in Arabic. Each interview lasted approximately 30 minutes. The interviewer took handwritten notes that were translated into English by the interviewer. The interviewers were fluent in both Arabic and English and were best able to represent the meaning of the students in their translations.

Interview questions reported on in this paper related to students' perceptions of their ability to discuss ideas and to investigate and test ideas and were asked in both the pre-introduction and post-introduction interviews

- How well do you feel you can discuss ideas about mathematics with each other in your lessons?

- How well do you feel you can investigate and test out your own ideas in mathematics?

- Do you think inquiry-based lessons can help you in learning mathematics and how?

In the post-introduction interview students were also asked if they felt that the WebQuest lessons had helped their learning.

- Did you feel that the WebQuest lessons helped you in learning mathematics? If so how?

All the interview responses were kept anonymous and confidential. Data were collected from the FGs in a way that did not allow for the tracking of individual students' prospect-based and retrospect-based reactions. Instead, the data allowed for the determination of differing viewpoints within and across the FGs. 
Table 2. Analytical process of FG interview data across descriptive categories and emotion-based themes

\begin{tabular}{|c|c|c|c|}
\hline & Stage & & Comparison \\
\hline \multirow[t]{2}{*}{$\begin{array}{l}\text { Descriptive } \\
\text { categories }\end{array}$} & Prospective & $\begin{array}{l}\text { Self-direction } \\
\text { Collaboration } \\
\text { Support for learning }\end{array}$ & \\
\hline & Retrospective & $\begin{array}{l}\text { Self-direction } \\
\text { Collaboration } \\
\text { Support for learning }\end{array}$ & $\begin{array}{l}\text { Confirmed, changed or emerged } \\
\text { in retrospect }\end{array}$ \\
\hline \multirow[t]{2}{*}{$\begin{array}{l}\text { Emotion-based } \\
\text { themes }\end{array}$} & Prospective & $\begin{array}{l}\text { Desirability } \\
\text { Approbation } \\
\text { Attraction }\end{array}$ & \\
\hline & Retrospective & $\begin{array}{l}\text { Desirability } \\
\text { Approbation } \\
\text { Attraction }\end{array}$ & $\begin{array}{l}\text { Confirmed, changed or emerged } \\
\text { in retrospect }\end{array}$ \\
\hline
\end{tabular}

\section{Analytical Process and Framework}

Constant comparison inquiry (Butler-Kisber, 2018; Strauss \& Corbin, 1990), was used to interpret students' emotional reactions to the introduction of WebQuest lessons. This thematic qualitative inquiry approach was used to move from the descriptive categories of reactions found in the interview data to the conceptual themes related to trait-like emotions. In this way, the analysis was both deductive, in relating to synopses of text from the interview data, and inductive, in relating to conceptual contexts derived from literature on emotions and engagement. Initial deductive analysis was carried out in NVivo and involved coding interview synopses against three descriptive categories: student-directed learning (SD) (reactions related to students' changing role in responsibility for their learning without the direct instruction and explanation of the teacher); collaboration (COL) (reactions related to collaboration and group interactions); and support for learning (SFL) (reactions related to the students' interpretation of impact on their learning in mathematics). These categories were related to positive and negative valences (students' perceived advantages and disadvantages of the WebQuest lessons), both prospectively and retrospectively.

Synopses from the interview data were then analysed in relation to broader conceptual emotion-based themes drawn from Ortony, Close, and Collins' (1988) theory of the cognitive structure of emotions in relation to positive and negative valences. Whilst Ortony and Turner (1990) recognised a broader multi-dimensional view of emotions, the use of the positive and negative valences met our intentions to investigate students' perceived advantages and disadvantages. We do not refer to Ortony et al.'s full range of 22 emotion types, as we identify emotions grounded in the field text, nor do we consider variables affecting intensity of emotions. Instead, we frame the analysis loosely on that used by Martinez-Sierra and Garcia-González (2017) (also drawn from Ortony et al.'s theory) to analyse students' emotions in mathematics classes. This framework relates to three situations: 1) the desirability of the consequences of an event; 2) approbation of the actions of agents (themselves or others); and 3) the attraction of an object.

Our framing of these concept-based themes was used to determine: 1) students' desirability, that is the congruence of the consequences of the WebQuest lessons to their personal goals in learning mathematics; 2) students' approbation, that is their approval/appreciation or their disapproval/reproach of their or other's actions within the dialectic interplay; and 3) students' attraction to the WebQuest lessons as objects, that is the correspondence of aspects of the WebQuest lessons with their individual likes, whether they found them appealing or unappealing. Table 2 sets out the analytical process, indicating the comparison across descriptive categories and emotion-based themes and across prospect and retrospect-based reactions.

\section{ANALYSIS AND RESULTS}

Our intention in carrying out a cross case analysis of the descriptive categories was to compare the valence of students' reactions across the FGs both prospectively and retrospectively. In addressing research question 1 , we wished to determine in what ways the introduction of WebQuest lessons might have impacted on the students' reactions to a more student-oriented collaborative approach to learning. 


\section{Descriptive Categories: Synopses of Interviews}

Students' responses to questions related to their ability discuss and investigate ideas and to the use of inquiry to support their learning were coded in relation to three descriptive categories: student-directed learning (SD), collaboration (COL), and support for learning (SFL).

\section{Student-directed learning}

Some students' prospective reactions suggested they saw advantages in moving towards student-directed learning. Students in two of the FGs suggested that they already experienced some problem-solving work in their mathematics classes. Students in FG P indicated that their teacher already prepared problems that required them to think, and in FG L students indicated that their teacher gave them issues with higher thinking skills. Some students in FG L went on to say that they would be "more satisfied if we find the answer by ourselves." Positive prospective reactions also related to self-reliance and searching for information:

FG M (Prospective): We feel comfortable because we will rely on ourselves. We want to look for information more by ourselves. (SD).

However, some students' prospective reactions were negative. For example, some students in FG J stated that they preferred the teacher to direct their learning. They felt their teacher gave clear explanations and made learning easy.

In two of the FGs students indicated contrasting prospective reactions to self-directed learning. Whilst some students in FG L indicated they would be satisfied to find answers themselves, other students indicated they preferred to follow the teacher. Such contrasting prospective reactions were also evident in FG K:

FG K (Prospective): We need to investigate by ourselves. (SD)

FG K (Prospective): We feel comfortable when the teacher tells us ideas because she knows more than us. (SD)

Some students' retrospective reactions suggested that self-directed learning had been an advantage. Students in FG P indicated the opportunities they had to learn this way:

FG P (Retrospective): Learning depends on students not on the teacher. We were given the opportunities to search for the information without depending on teachers all the time. (SD).

Students in FG M also referred to self-directed learning as an advantage in the WebQuest lessons, and that they almost seemed surprised that they had learned this way:

FG M (Retrospective): We learned by ourselves, believe us we solved the exercises in the textbook without any help from the teacher. It was wonderful to reach goals ourselves without any help from the teacher. (SD).

Students in FGK had contrasting prospective reactions about self-directed learning and the positive and negative valences remained with some students referring to confidence in working this way whilst others expressing a dislike:

FG K (Retrospective): We like it [the WebQuest]. It gave us the confidence to learn the information by ourselves. (SD).

FG K (Retrospective): I liked when the teacher explained the lesson herself. (SD)

\section{Collaboration}

Some students, prospective reactions suggested that they already had a good environment to discuss ideas (FG P), however, other students in FG O suggested they were unfamiliar in working this way but indicated advantages in sharing ideas in collaboration.

FG O (Prospective): Although some of us never tried this before, but we think yes, it is a great way to know the others' ideas, opinions, and experiences. (COL) 
As indicated in reactions related to self-directed learning, students in some FGs had contrasting reactions. For example, some students in FG K suggested they were comfortable to share ideas, whereas some students suggested that other students would confuse them:

FG K (Prospective): We feel comfortable when we discuss math ideas. (COL)

FG K (Prospective): I don't like discussing ideas in math lessons because other students will confuse me. (COL)

These contrasting perspectives were also evident in FG L. It appeared that some students could work constructively together whereas others suggested disagreements:

FG L (Prospective): We all agree on one answer and each member has an opportunity to explain her point of view. (COL)

FG L (Prospective): Sometimes we disagree about who has the right answer. (COL)

Some students in FG M also referred to disruptions in group work or a lack of cooperation:

FG M (Prospective): Some of the students shout and laugh at us if our answer is wrong.

The smart student is the one who dictates the answers. (COL).

Whilst some students in FG M referred to non-constructive group work, their concerns were not confirmed in the retrospective reactions. Although students admitted to being uncertain initially it appears that they became more comfortable working collaboratively.

FG M (Retrospective): We were happy to discuss ideas, with a little bit confused at first. (COL).

Students in FG L and FG O also saw collaboration as an advantage of the WebQuest lessons. Students in FG $\mathrm{O}$ had all been positive prospectively about collaboration and these reactions seemed to be confirmed:

FG O (Retrospective): By working in groups or pairs we can help each other (COL).

Students in FG L had contrasting reactions prospectively and these contrasting reactions remained with some students suggesting constructive work together whilst others indicated disputes.

FG L (Retrospective): We were comfortable to discuss our ideas about mathematics. (COL).

FG L (Retrospective): Sometimes we fight when we discuss ideas about mathematics. We don't have enough confidence to discuss our ideas about mathematics. (COL)

\section{Support for learning}

Prospectively, students in FG P felt that the introduction of inquiry would stimulate their thinking and "show up out talents and improve our skills" (SFL). Other students felt that they would increase their understanding and helped in memorization, or that they would have opportunities for self-evaluation:

FG N (Prospective): We will be able to increase understanding and we will not forget the whole learning process. (SFL)

FG J (Prospective): It [investigation] will provide the opportunity for us to evaluate our self and correct the mistakes. (SFL)

As many students had not experienced working this way, they were not always able to express a reaction. However, students in FG I stated that they did not know what inquiry was and yet they expressed concern that inquiry would not support their learning (SFL). Students in FG I continued to give negative reactions in retrospect, suggesting that they did not achieve in their learning or that they needed the teacher to help understand.

FG I (Retrospective): I think I need teacher help to understand and need to ask about while studying. (SFL) 
Table 3. Comparison of descriptive categories across FGs and stages

\begin{tabular}{|c|c|c|c|c|c|}
\hline & \multicolumn{3}{|c|}{$\begin{array}{c}\text { Confirmed (prospective and } \\
\text { retrospective) }\end{array}$} & \multicolumn{2}{|c|}{ Emerged retrospectively } \\
\hline & Focus Group (FG) & Positive & Negative & Positive & Negative \\
\hline \multirow{3}{*}{ Common valences } & I Gr 8 Boys & & SD; SFL & & \\
\hline & O Gr 7 Boys & $\mathrm{COL}$ & & SFL & \\
\hline & P Gr 9 Girls & SD; COL & & & \\
\hline \multirow{3}{*}{ Mixed valences } & J Gr 5 Girls & SD; SFL & SFL & COL & COL \\
\hline & K Gr 7 Girls & SD; SFL & SD; COL & & \\
\hline & L Gr 5 Girls & $\mathrm{SD} ; \mathrm{COL}$ & $\mathrm{COL}$ & SFL & \\
\hline \multirow{2}{*}{$\begin{array}{l}\text { Common/mixed } \\
\text { valences }\end{array}$} & Ma Gr 5 Girls & $\mathrm{SD} ; \mathrm{COL}$ & & SFL & \\
\hline & $\mathrm{Nb}^{\mathrm{b}}$ Gr 5 Girls & SFL & & & SFL \\
\hline
\end{tabular}

SD = Student-direction; COL= Collaboration; SFL= Support for learning

$\mathrm{M}^{\mathrm{a}}$ Negative valence COL not confirmed; $\mathrm{N}^{\mathrm{b}}$ Negative valence SFL emerged.

Students in FGs J and $\mathrm{N}$ also felt that they did not achieve in their learning retrospectively, but other students in these groups saw advantages to their learning:

FG J (Retrospective): It [WebQuest] motivates us to seek and enrich information even outside the classes. (SFL)

FG N (Retrospective): It [WebQuest] put us in challenge with ourselves. It's pushing us to seek and enrich information (SFL)

Student in FG O were also positive about the experience in relation to their learning indicating that the use of different media had been supportive:

FG O (Retrospective): Through working in different types of activities, videos, and interactive web sites, besides using different resources and producing a product. (SFL)

\section{Comparison of prospective and retrospective reactions across FGs}

In response to research question 1, we consider in what ways the introduction of WebQuest lessons confirmed or changed students' reactions to a student-oriented collaborative approach to learning. Table 3 indicates where the valence of reactions in relation to the descriptive categories were confirmed or emerged for each FG. This comparison illustrates how students in some FGs gave reactions within a common valence within the same group and that these valences were confirmed. Three main groupings emerged:

1) the valence of students' reactions was common in a group and were confirmed (FGs I, O, and P):

2) students suggested mixed valence reactions prospectively and retrospectively (FGs J, K, L);

3) students' reactions were either mixed prospectively and became positive retrospectively (FG M) or were positive prospectively and became mixed retrospectively (FG N).

Where valences were common within an FG, then existing classroom norms and teacher influence may have been a factor. However, where the valence of reactions was mixed both before and after the introduction of WebQuest lessons, it is not so clear that existing classroom norms and teacher influence in implementing the lessons would have been a factor.

For example, students in FGs I, O, and P suggested retrospective reactions that confirmed the valence of their prospective reactions. For FG I, students were negative towards the introduction of inquiry in relation to self-directed learning and support for learning and remained so following the WebQuest lessons. They had indicated unfamiliarity with inquiry and their prospective reactions suggested they were uncertain if inquiry would help them learn mathematics. This reaction was confirmed in retrospect with students indicating they needed their teacher to help them understand. Students in FGs O and P students were positive towards the introduction of inquiry and remained so following the WebQuest lessons. Students in FG O had also been unfamiliar. Prospectively, they saw benefit in collaboration, and this was confirmed. In addition, support for learning emerged with reference to a range of media. Students in FG P indicated an existing collaborative and problem-solving environment and perceived that inquiry would sharpen their skills. They remained positive about student-directed learning following the introduction of WebQuest lessons. For these FGs, the valence of retrospective reactions appeared to be contingent on their prospective reactions and may even have been contingent on their initial experiences of classroom norms. 
In other groups (J, K, and L) mixed valence reactions were evident prospectively and retrospectively. For example, in FG K, some students suggested potential advantages in self-directed learning prospectively and this was confirmed. In retrospect, they indicated that the WebQuest lessons had supported their confidence in student-directed learning. Students in FG K also had concerns about self-directed learning and collaboration and these concerns were also confirmed. Mixed valences were also evident in FG L in relation to collaboration even though some students had indicated existing classroom experiences that encouraged higher order thinking and collaboration.

In FG M only the positive valence reactions were confirmed. Some students had suggested they were already comfortable in collaboration and liked the notion of student-direction whereas others indicated lack of cooperation and disputes in group work. However, the potential disadvantages did not seem to be confirmed retrospectively for students in FG $\mathrm{M}$. Whilst some students had indicated their uncertainty about the WebQuest lessons initially, they enthused about student-directed learning retrospectively, and even seemed surprised that they had learned this way, and they also indicated how they overcame some confusion about working collaboratively. Changes were also evident for students in group N. All students had indicated advantages in introducing inquiry in relation to challenges and enhanced understanding and these reactions appeared to be confirmed retrospectively for some students. However, some students in FG N indicated retrospectively that they did not achieve any learning from the WebQuest lessons. They did not feel that they could test out and investigate their own ideas and they did not like discussion and participation in groups.

\section{Confirmation or Emergence of Emotion-based Themes}

In response to research question 2, we identified the emotions expressed in the reactions and how they were confirmed, changed or emerged. Analysis in relation to conceptual themes are used to further examine how valences were confirmed in relation to the emotions encoded in the reactions. Table 4 sets out the three emotion-based themes, desirability, approbation and attraction. These are illustrated with extracts from the interview synopses. FGs and codes for descriptive categories have been identified.

In relation to desirability, emotions evident in the interview synopses suggest that some students were pleased prospectively, suggesting that the congruence of consequences of the WebQuest lessons related to their goals in learning mathematics. Some students were hopeful (it will...) or desirous (we want... we need...) in anticipating inquiry as supporting their learning or suggested pride in being motivated and challenged. Retrospectively students were satisfied that their hopes or desires had been met or that they gained confidence in student-directed learning. Other students were apprehensive about the introduction of inquiry prospectively and suggested disappointment in not achieving. These emotions suggested that the consequences of the WebQuest lessons were not congruent with their learning goals.

In relation to approbation, some students indicated prospectively that they appreciated the actions of others as they were already comfortable to work this way (we were happy...) or anticipated that they would appreciate the action of others in collaboration (it is a great way...). These emotions appeared to be confirmed as comfort or the acceptance of help from others when working collaboratively. Other students suggested reproach for the actions of others. This reproach emanated prospectively as humiliation (I feel embarrassed...) and fear (we are afraid...) and confusion (other students will confuse me...). This reproach was confirmed in retrospect as students felt discomfort in the action of others due to disputes (sometimes we fight...) and lack of confidence. Reproach also related to deference to the teacher as authority of knowledge prospectively (the teacher knows more...).

In relation to attraction, none of the students suggested that the WebQuest lesson, as an object, was appealing prospectively. The question directly related to WebQuest lessons was asked in the post-introduction interview, so students were not focused on the WebQuest lessons as an object prospectively. However, in retrospect students found aspects of WebQuest lessons appealing and corresponded with their individual likes. These students suggested other emotions such as interest, fun or elation. One student had indicated dislike as a way of learning prospectively, suggesting aspects of inquiry did not correspond to their individual preferences. This dislike was both confirmed and emerged for students in FG K and N. In reviewing the interview responses for appreciation, students that found WebQuest lessons unappealing had either indicated dislike prospectively (FG J) or had indicated negative valence emotions for reproach prospectively. Students that found WebQuest lessons appealing had indicated positive emotions for desirability (FG K) or for desirability and approbation (FGs L and M). 
Table 4. Prospective and retrospective emotion-based themes

\begin{tabular}{|c|c|c|c|}
\hline Theme & Valence & Prospective & Retrospective \\
\hline \multirow[t]{7}{*}{ Desirability } & Pleased & $\begin{array}{l}\text { FGJ: It will provide opportunity...(SFL) } \\
\text { FGK: We need to investigate... (SD) }\end{array}$ & FGJ: It motivates us...(SFL) \\
\hline & & FGL: It will make learning easier...(SFL) & FGK: It gave us confidence to learn by \\
\hline & & FGM: We want to look for information... & ourselves...(SD) \\
\hline & & (SD) & FGL: We generate new ideas...(SFL) \\
\hline & & FGN: We will increase & FGM: We learned by ourselves, believe \\
\hline & & understanding...(SFL) & us...(SD) \\
\hline & Displeased & FGI: It will not help learning ...SFL) & FGI: We did not achieve (SFL) \\
\hline \multirow[t]{5}{*}{ Approbation } & Appreciation & FGL: We all agree... (COL) & $\begin{array}{l}\text { FGL: We were comfortable to share } \\
\text { ideas...(COL) }\end{array}$ \\
\hline & & $\begin{array}{l}\text { FGM: We feel comfortable to rely on } \\
\text { ourselves...(SD) }\end{array}$ & $\begin{array}{l}\text { FGM: We were happy to share } \\
\text { ideas...(COL) }\end{array}$ \\
\hline & & $\begin{array}{l}\text { FGO: It is a great way to know others' } \\
\text { ideas...(COL) }\end{array}$ & $\begin{array}{l}\text { FGO: By working in groups we can help } \\
\text { each other... COL) }\end{array}$ \\
\hline & Reproach & $\begin{array}{l}\text { FGK: Other students will confuse } \\
\text { me...(COL) The teacher knows more than } \\
\text { us...(SD) }\end{array}$ & $\begin{array}{l}\text { FGK: I liked when the teacher } \\
\text { explained...(SD) }\end{array}$ \\
\hline & & $\begin{array}{l}\text { FGL: Sometimes we disagree...(COL) I feel } \\
\text { embarrassed...We are afraid our answer is } \\
\text { wrong...(SFL) }\end{array}$ & $\begin{array}{l}\text { FGL: Sometimes we fight...We don't } \\
\text { have enough confidence to share } \\
\text { ideas...(COL) }\end{array}$ \\
\hline \multirow[t]{4}{*}{ Attraction } & Like & & FGK: We like it... (SD) \\
\hline & & & $\begin{array}{l}\text { FGL: WebQuests were fun, } \\
\text { interesting... (SFL) }\end{array}$ \\
\hline & & & $\begin{array}{l}\text { FGM: It is excellent... (SFL). It was } \\
\text { wonderful... (SD) }\end{array}$ \\
\hline & Dislike & FGJ: I prefer the traditional way...(SD) & $\begin{array}{l}\text { FGJ: We do not like } \\
\text { participation...(COL) } \\
\text { FGK and FGN: We did not like this way } \\
\text { of learning...(SD) }\end{array}$ \\
\hline
\end{tabular}

\section{DISCUSSION}

The aim of the study presented in this paper was to determine if the introduction of WebQuests and exploratory talk would help to overcome the potential challenges and stresses experienced by students in moving towards collaborative inquiry. Prospective reactions indicated that many students perceived advantages in making this shift. Emotions evident in these positive reactions suggested students felt that learning this way was rewarding and interesting. Some students seemed proud to be challenged and pushed in their learning, and the emergence of emotions such as elation and enjoyment further suggested enhanced engagement. In contrast, other students perceived disadvantages in making this shift. They reacted negatively to the increased control and direction of their learning. The reactions of these students indicated that their engagement was not enhanced and that they did not feel their learning was supported.

Comparison between prospective and retrospective reactions and emotion-based themes suggested that the valence of the reactions and emotions was often confirmed. Previous orientations of teaching and teacher influence in implementing the strategies could explain how students in some FGs were more accepting of the WebQuest lessons, but the mixed valences that remained within other FGs could not be fully explained by teacher influence and class environment. One explanation for the confirmation of the mixed valences within each FG is that the students' reactions expressed individual traits that became evident in their emotions. Whilst individual students were not tracked in the interviews, it is possible that these confirmed valences may have related to the emotional traits of the same students within each FG. We further consider this assumption in relation to the literature in response to research question 3: How might the confirmation, transformation or emergence of emotions indicate traits related to inquiry approaches to learning in mathematics?

A key intention for using WebQuests and exploratory talk was to introduce a collaborative inquiry approach and move towards student-direction where students had control over an activity. This perceived control was intended to help students see the value of an activity and respond positively (Pekrun, 2006). The findings in this study suggested that many students did react positively. The consequences of taking control of their learning pleased them, they appreciated the actions of others, and they liked the experience. As such, 
they appeared to value this way of working, and their engagement was enhanced. However, this was not the case with all students. For some students, the consequences of taking control of their learning displeased them, they were reproachful of the actions of others and disliked the experience. As such, they did not appear to value this way of working and their engagement was diminished.

A key aspect of introducing exploratory talk was to move towards a collaborative approach. Some students felt comfortable in collaborative group work and felt that discussions of different ideas benefited their understanding and encouraged them to be critical and to evaluate their ideas. They were able to create reciprocal relationships that enhanced their engagement (Linnenbrink-Garcia, Rogat, \& Koskey, 2011). Other students related to disagreements and referred to disputes over incorrect answers with suggested consequences of confusion, humiliation, and discomfort. These students were unable to establish reciprocal relationships and were not engaged. Sinha, Rogat, Adams-Wiggins, and Hmelo-Silver (2015) suggested that collaboration and technology are not necessarily the panacea for student engagement in learning and that group work raises challenges for maintaining engagement and for coordinating multiple perspectives. Some Qatari students seemed able to maintain engagement and coordinate multiple perspectives in a way that was rewarding. For other students, the coordination of perspectives was uncomfortable and distressing. It is possible that some students experienced groups that did not adopt strategies for exploratory talk well. However, if we see that engagement in collaborative group work relates to both social and individual processes (Järvelä, Volet, \& Järvenoja, 2010), one explanation is that some individual students were less able to tolerate dialectic interactions. This lack of ability may have related to emotional traits towards increased responsibility in determining authority of knowledge in a critical and reciprocal way.

The contrasting student reactions in relation to student-direction and collaboration are further reflected in relation to tolerance for ambiguity within dialectic interplay in determining knowledge, and in relation to the acceptance of the roles and responsibilities in student direction. The emotions evident in the students' reactions suggested individual traits regarding tolerance for ambiguity and responsibility for learning. The emotions of some students suggested they were predisposed towards ambiguity and responsibility. Where emotions were confirmed in the positive valence, students appreciated being challenged dialectically and seemed elated by the changing role. These were the students who found criticisms to be exciting and interesting and felt their learning and thinking was enhanced. Such students were tolerant of ambiguity. They had an ability to perceive uncertainties, contradictions and multiple meanings in an open way (Bochner, 1965; Frenkel-Brunswik, 1949; Macdonald, 1970; Mclain, Kefallonitis, \& Armani, 2015). Where emotions were confirmed in the negative valence, students found the disagreements and criticisms uncomfortable or stressful (Goldin, Epstien, Schorr, \& Warner, 2011). Lack of tolerance for ambiguity meant that they found the potential wrong answers confusing. Such students were fearful of collaboration and deferred to the authority of the teacher to provide explanations and directions for their thinking.

We propose that the external expressions of affect regarding the ability to tolerate ambiguity and take responsibility for learning points towards trait-like emotions. They imply individual patterns in and across individuals towards the learning situations and may relate to engagement structures (Goldin et al, 2014). For example, where students suggested that introducing WebQuests would "show off our talents" and that they were being pushed or challenged in their learning, they reflected traits similar to Look How Smart I Am, suggesting they valued mathematical ability. Where students indicated positive emotions in relation to being pleased that it motivated them, or that they gained confidence to learn by themselves and to gain new information, they reflected traits similar to Check This Out as they appeared to obtain a reward from the experience. Other students indicated pleasure, elation, deep engagement, and satisfaction in understanding and reflected traits similar to I'm Really Into This. Where some students indicated comfort in sharing ideas, they may have related to the trait Let Us Learn Together.

Examples in relation to negative emotions also indicated trait-like characteristics. Some of the students' emotions appeared to indicate avoidance of conflict or situations that they interpreted as fights and may have related to the trait Stay Out Of Trouble. Other students appeared to avoid situations that belittled or humiliated them or threatened their dignity and may have related to the trait Don't Disrespect Me. Other emotions appeared to relate to deference to the authority of the teacher and a resistance to the challenge of self-directed learning. Goldin et al. suggested that emotions tied to teacher telling and explaining would "override the issue of understanding the math" (Goldin et al., p. 553). Whilst it is possible that the deference exhibited by students in this study suggested a trait-like lack of tolerance for ambiguity, it is not so clear that this was intended to override an issue of understanding. These students were afraid "what if I am wrong," "I need the teacher to help me understand," or "other students confuse me." There is almost a sense of rejection 
and disappointment that they no longer have the teacher explanation to help them understand. The issue was not in overriding understanding but in determining the authority of the teacher in understanding, rather than fellow students.

\section{Considerations of Limitations and Benefits}

We recognise that there were both benefits and limitations in the data collection methods and analytical processes. Interview data were not collected in a way to track individual students, but we can surmise that, for some students in the same FGs, the valences may not have changed. The interviews were recorded as field notes by researchers in Qatar and translated from Arabic into English for analysis. The researchers were present in the interview, so they were the most appropriate to represent the ideas of the students. However, terms recorded and then translated may not be exactly those intended by the students. We also recognise that, whilst there were benefits of working with prospective and retrospective reactions as narrative verbal components in that they were more likely to be trait-like, analysis of narratives from these emotional experiences differ from the direct analysis of emotions and further studies are needed to explore the direct emotions in relation to transition trait-like emotions.

In this article we do not consider the impact of the teacher on students' reactions. Issues such as lack of cooperation in group work might have been due to a lack of teacher management. However, students in the same FG gave contrasting reactions suggesting that teacher management and class environment were not the only influence. We also acknowledge that students had been working in this way over a short period of time. Further WebQuest lessons and development of the strategies by the teachers could help students tolerate ambiguity and so move towards more positive reactions. For example, Pijls (2007) found that, with further teacher specific direction towards collaboration, students could become more able to work within collaboration. Nevertheless, the prospective and retrospective reactions were ones that teachers would encounter with students as they introduce inquiry approaches and may explain why, even if practical classroom strategies are provided in PD programmes, many teachers abandon their use early on and return to traditional practices.

The focus of the study presented in this paper is on student reactions, the evidence of emotions within these reactions, and how these emotions can help us understand typical behavioural characteristics. It is purported that these behavioural characteristics are reactions to the ambiguity inherent in the dialectic interplay of collaborative student-directed learning experiences and that behavioural and emotional traits may go beyond the implementation of the teacher. Whilst Goldin et al.'s (2011) studies on engagement structures and Martinez-Sierra and Garcia-González's (2017) analytical framework for emotions were based on problem-solving in mathematics classes, our study took the context to be collaborative student-centred inquiry rather than the specifics of problem solving.

\section{CONCLUDING STATEMENT}

A review of the trait-like emotions encoded in the students' prospective and retrospective reactions in relation to Goldin et al.'s engagement structures suggested that students held contrasting beliefs and values about collaborative inquiry approaches. Whilst some students appreciated the level of ambiguity and critical engagement with other students and felt reward came from student-direct learning, others felt that reward came from gaining clear explanations from an adult who knows more than them. These different values may have been underpinned, not just by the students' ability to tolerate ambiguity, but by an appreciation that ambiguity might support their learning in mathematics.

In this regard, two main emotion-based groups emerged: those with a preference for monologic teacherdirected approaches and those with a preference for dialectic student-directed approaches. Reactions of students in the monologic preference group suggested they found the ambiguity of student-directed learning uncomfortable with the potential for making mistakes and lack of explanation to help them understand. In the emotion-based themes, students in the monologic preferred group suggested displeasure, reproach and dislike. They were disappointed about not achieving, continued to feel dependent on the teacher and discomfort in group work, and were dejected by the experience. Reactions of students in the dialectic preferred group suggested they wanted and enjoyed the challenge of ambiguity and found that alternative viewpoints helped them to learn and understand. In the emotion-based themes, students within the dialectic preferred group suggested pleasure, appreciation and like. They wanted to be challenged and to rely on their own thinking and were comfortable to share ideas in group work. It is possible that the introduction of WebQuest lessons enhanced the engagement of those students whose emotional traits were disposed towards tolerance of 
ambiguity but did little to enhance the engagement of those students who were disposed towards intolerance of ambiguity.

If we accept that in mathematics students should be prepared for inquiry-based learning in 21st century, we need to appreciate fully what it means for students to move towards learning experiences where their emotions towards teacher and student direction in learning may be put under stress. We need to understand ways to help these students value such approaches as rewarding experiences, and to realise that ambiguity, rather than confusing them and making them uncomfortable, can increase their understanding.

A key issue presented in the context of this study was that PD in Qatar had not been effective. Teachers experience their own challenges in introducing inquiry approaches in their classrooms. If they are also seeing and managing negative reactions from their students, this might exacerbate their own challenges and explain why, despite PD providing practical classroom management strategies, some teachers may be reluctant to continue working this way. Recognising students' emotional character traits as engagement structures may help researchers and practitioners to overcome students' resistance or reluctance to engage in the introduction of inquiry approaches.

Research on students' experiences when introduced to inquiry approaches is still limited. Students need guidance in working this way (Lazonder \& Harmsen, 2016), but this guidance may also be nuanced by different behavioural and emotional characteristics. Further in-class in-the-moment studies of students working with the dialectic nature of collaborative inquiry is needed. The focus is often on performance, but we also need to understand how to help some students value ambiguity early in the introduction of newer richer pedagogies.

\section{ACKNOWLEDGEMENT}

This paper was made possible by NPRP grant \# 8-631-5-076 from the Qatar National Research Fund (a member of Qatar Foundation). The findings achieved herein are solely the responsibility of the authors.

\section{Disclosure statement}

No potential conflict of interest was reported by the authors.

\section{Notes on contributors}

Carol Murphy - University of Tasmania, Australia.

Nigel Calder - University of Waikato, New Zealand.

Nasser Mansour - University of Exeter, United Kingdom.

Abdullah Abu-Tineh - Qatar University, Qatar.

\section{REFERENCES}

Ajzen, I. (2001). Nature and operation of attitudes. Annual Review of Psychology, 52, 27-58. https://doi.org/10.1146/annurev.psych.52.1.27

Artigue, M., \& Blomhoej, M. (2013). Conceptualising inquiry-based education in mathematics. ZDM Mathematics Education, 45(6), 797-810. https://doi.org/10.1007/s11858-013-0506-6

Attard, C. (2014). I don't like it, I don't love it, but I do it and I don't mind: introducing a framework for engagement with mathematics. Curriculum Perspectives, 34(3), 1-14.

Barnes, D. (1975). From communication to curriculum. Harmondsworth, Middlesex, UK; Penguin Books Ltd.

Bochner, S. (1965). Defining tolerance of ambiguity. The Psychological Journal, 15(3), 393-400. https://doi.org/10.1007/BF03393605

BouJaoude, S. (2003). Achievement levels of new school project students in grades 1 to 5 in Arabic, math, and science. Project funded by the Education Development Center Inc., Newton, MA, USA.

Butler-Kisber, L. (2018). Qualitative inquiry: Thematic, narrative and arts-based perspectives (2nd Ed.) London, UK: Sage Publications Ltd.

Calder, N. (2011). Processing mathematics through digital technologies. Rotterdam, The Netherlands: Sense. https://doi.org/10.1007/978-94-6091-627-4 
Calleja, J. (2016) Teaching Mathematics Through Inquiry: A continuing professional development programme design. Educational Designer, 3(9), 1-29.

Crano W. D., \& Prislin, R. (2006). Attitudes and persuasion. Annual Review of Psychology, 57, 345-374. https://doi.org/10.1146/annurev.psych.57.102904.190034

Di Martino, P., \& Zan, R. (2001). Attitude toward mathematics: some theoretical issues. Proceedings of PME 25, vol. 3, 351-358, Utrecht, Netherlands.

Dodge, B. (1995). WebQuests: A technique for internet-based learning. Distance Educator, 1(2), 10-13.

Dole, S., Bloom, L., \& Kowalske, K. (2016). Transforming pedagogy: Changing perspectives from teachercentred to learner-centred. Interdisciplinary Journal of Problem-Based Learning, 10(1), Article 1. https://doi.org/10.7771/1541-5015.1538

Edens, K. M. (2000). Preparing Problem Solvers for the 21st Century through Problem-Based Learning. College Teaching, 48(2), 55-60. https://doi.org/10.1080/87567550009595813

Foster, C. (2014). Minimal interventions in the teaching of mathematics. European Journal of Science and Mathematics Education, 2(3), 147-154.

Frenkel-Brunswik, E. (1949). Intolerance of ambiguity as an emotional and perceptual personality variable. Journal of Personality, 18, 108-143. https://doi.org/10.1111/j.1467-6494.1949.tb01236.x

Frenzel, A., Goetz, T., Pekrun, R., \& Watt, H. (2010). Development of Mathematics Interest in Adolescence: Influences of Gender, Family, and School Context. Journal of Research on Adolescence, 20(2), 507-537. https://doi.org/10.1111/j.1532-7795.2010.00645.x

Fullan, M., \& Langworthy, M. (2014). A rich seam: How new pedagogies find deep learning. London, UK: Pearson.

Gluckman, P. (2011). Looking ahead: Science education for the twenty-first century: A report from the Prime Minister's Chief Science Advisor. Auckland, New Zealand: Office of the Prime Minister's Science Advisory Committee.

Goldin, G. A. (2014). Perspectives on emotion in mathematical engagement, learning, and problem solving. In R. Pekrun \& L. Linnenbrink-Garcia (Eds.), Handbook of emotions in education (pp. 391-414). New York, NY: Taylor \& Francis. https://doi.org/10.4324/9780203148211

Goldin, G. A., Epstein, Y. M., Schorr, R. Y., \& Warner, L. B. (2011). Beliefs and engagement structures: Behind the affective dimension of mathematical learning. ZDM Mathematics Education, 43, 547-560. https://doi.org/10.1007/s11858-011-0348-z

Grant, M. M., \& Hill, J. R. (2006). Weighing the risks with the rewards: Implementing student centered pedagogy within high-stakes testing. In R. Lambert \& C. McCarthy (Eds.), Understanding teacher stress in an age of accountability (pp. 19-42). Greenwich, CT: Information Age Press.

Hannula, M. S. (2002). Attitude towards mathematics: Emotions, expectations and values. Educational Studies in Mathematics, 49, 25-46. https://doi.org/10.1023/A:1016048823497

Hattie, J. A. C. (2009). Visible learning: A synthesis of over 800 meta-analyses relating to achievement. New York, NY: Routledge. https://doi.org/10.4324/9780203887332

Järvelä, S., Volet, S., \& Järvenoja, H. (2010) Research on motivation in collaborative learning: Moving beyond the cognitive-situative divide and combining individual and social processes. Educational Psychologist, 45(1), 15-27. https://doi.org/10.1080/00461520903433539

Kind, P. M., Jones, K., \& Barmby, P. (2007). Developing attitudes towards science measures. International Journal of Science Education, 29(7), 871-893. https://doi.org/10.1080/09500690600909091

Knowles, M. S. (1975). Self-directed learning: A guide for learners and teachers. New York: Association Press.

Lappas, P., \& Kritikos, M. (2018). Teaching and Learning Numerical Analysis and Optimization: A Didactic Framework and Applications of Inquiry-based Learning. Higher Education Studies, 8(1), 42-57. https://doi.org/10.5539/hes.v8n1p42

Lazarides, R., \& Rubach, C. (2017). Instructional characteristics in mathematics classrooms: relationships to achievement goal orientation and student engagement. Mathematics Education Research Journal, 29, 201-217. https://doi.org/10.1007/s13394-017-0196-4

Lazonder, A. A., \& Harmsen, R. (2016). Meta-analysis of inquiry-based learning: Effects of guidance. Review of Educational Research, 86(3), 681-718. https://doi.org/10.3102/0034654315627366 
Lederman, N. G., Lederman, J. S., \& Antink, A. (2013). Nature of science and scientific inquiry as contexts for the learning of science and achievement of scientific literacy. International Journal of Education in Mathematics, Science and Technology, 1(3), 138-147.

Liljedahl. P., Oesterle, S., \& Bernèche, C. (2010). Beliefs as dynamic: Old light through a new window. Proceedings of the 15th international conference on Mathematical Views (MAVI). Genoa, Italy.

Linnenbrink-Garcia, L., Rogat, T. K., \& Koskey, K. L. K. (2011). Affect and engagement during small group $\begin{array}{lllll}\text { instruction. } & \text { Contemporary } & \text { Educational } & \text { Psychology, }\end{array}$ https://doi.org/10.1016/j.cedpsych.2010.09.001

Lipman, M. (2003). Thinking in education (2nd ed.). Cambridge, England: Cambridge University Press. https://doi.org/10.1017/CBO9780511840272

Lipscomb, G. (2003). "I Guess It Was Pretty Fun”: Using WebQuests in the middle school classroom, The Clearing House, 76(3), 152-155. https://doi.org/10.1080/00098650309601993

Littleton, K., \& Mercer, N. (2013). Interthinking: Putting talk to work. Abingdon, England: Routledge. https://doi.org/10.4324/9780203809433

Maas, K., \& Artigue, M. (2013). Implementation of inquiry-based learning in day-to-day teaching: A synthesis. ZDM Mathematics Education, 45(6), 779-795. https://doi.org/10.1007/s11858-013-0528-0

Mansour, N., \& Wegerif, R. (2013) Why science education for diversity. In N. Mansour \& R. Wegerif (Eds.) Science education for diversity: Theory and Practice (pp. 3-22). Dordrecht, The Netherlands: Springer. https://doi.org/10.1007/978-94-007-4563-6

Martínez-Sierra, G., \& García-González, M. (2017). Students' emotions in the high school mathematics class: Appraisals in terms of a structure of goals. International Journal of Science and Mathematics Education, 15, 349-369. https://doi.org/10.1007/s10763-015-9698-2

McLain, D. L., Kefallonitis, E., \& Armani, K. (2015). Ambiguity tolerance in organizations: definitional clarification and perspectives on future research. Frontiers in psychology, 6,344 . https://doi.org/10.3389/fpsyg.2015.00344

McLeod, D. (1994). Research on affect and mathematics learning in the JRME: 1970 to the present. Journal for research in Mathematics Education, 25(6), 637-647. https://doi.org/10.2307/749576

Mercer, N., Wegerif, R. \&. Dawes, L. (1999) Children's talk and the development of reasoning in the classroom, British Educational Research Journal, 25(1), 95-111. https://doi.org/10.1080/0141192990250107

Mercer, N., \& Sams, C., (2006). Teaching children how to use language to solve maths problems. Language and Education, 20(6), 507-528. https://oi.org/10.2167/le678.0

Noording, N., Samed, A. A., \& Razali, A. B. (2008). ESL teacher-trainee reflections on the use of the WebQuest: Practical or just a hype? The English Teacher, 36, 66-80.

Ortony, A., Clore, G. L., \& Collins, A. (1988). The cognitive structure of emotions. Cambridge, United Kingdom: Cambridge University Press. https://doi.org/10.1017/CBO9780511571299

Ortony, A., \& Turner, T. (1990). What's Basic about Basic Emotions? Psychological Review 97, 315-331. https://doi.org/10.1037/0033-295X.97.3.315

Palmer, P., et al. (2016). A classroom observational study of Qatar's independent schools: Instruction and school reform. The Journal of Educational Research, 109(4), 413-422. https://doi.org/10.1080/00220671.2014.979908

Pekrun, R. (2006). The control-value theory of achievement emotions: Assumptions, corollaries and implications for educational research and practice. Educational Psychology Review, 18(4), 315-34. https://doi.org/10.1007/s10648-006-9029-9

Pijls, M. H. J. (2007). Collaborative mathematical investigations with the computer: learning materials and teacher help. Amsterdam: UvA/ILO.

Potvin, P., \& Hasni, A. (2014). Analysis of the decline in interest towards school science and technology from grades 5 through 11. Journal of Science Education and Technology, 23(6), 1-19. https://doi.org/10.1007/s10956-014-9512-x

Qatar National Research Strategy (QNRS) (2012). Qatar National Research Strategy (QNRS 2012): Executive Summary. Retrieved from https://www.qnrf.org/Portals/0/Download/QNRS_2012_Summary_Version_ 07082014.pdf

Salsovic, A. (2007). Integrating technology into the developmental mathematics classroom: A WebQuest. National Association for Developmental Education Digest, 3(1), 21-28. 
Said, Z., \& Friesen, H. (2013). Topic article: The impact of educational reform on science and mathematics education in Qatar. Paper presented at the International Interdisciplinary Conference, (AIIC). Azores, Portugal.

Sinha, S., Rogat, T. K., Adams-Wiggins, K. R., \& Hmelo-Silver, C. E. (2015). Collaborative group engagement in a computer-supported inquiry learning environment. International Journal of Computer-Supported Collaborative Learning, 10(3), 237-307. https://doi.org/10.1007/s11412-015-9218-y

Strauss, A., \& Corbin, J. (1990). Basics of qualitative research: Grounded theory procedures and techniques. Newbury Park, CA: Sage Publications.

Tafoya, E., Sunal, D. W., \& Knecht, P. (1980) Assessing inquiry potential: A tool for curriculum decision makers. School Science and Mathematics, 89(1), 43-48. https://doi.org/10.1111/j.19498594.1980.tb09559.x

Turner, J. C., \& Meyer, D. K. (2009). Understanding motivation in mathematics: What is happening in classrooms? In K. R. Wenzel \& A. Wigfield (Eds.), Educational psychology handbook series. Handbook of motivation at school (pp. 527-552). New York, NY, US: Routledge/Taylor \& Francis Group.

Üzel, D. (2012). WebQuest based learning: The attitudes of primary students towards mathematics. The New Educational Review, 27(1), 209-220.

Wells, G. (Ed.). (2001). Action, talk, and text: Learning and teaching through inquiry. New York, NY: Teachers College Press. 